\title{
George Louis Kline
}

The Board of Editors of Studies in East European Thought regrets to announce that George Louis Kline, Milton C. Nahm Professor Emeritus of Philosophy at Bryn Mawr College, died at the age of 93 in Anderson, South Carolina on October 21, 2014. Professor Kline served without interruption as a member of the board in both the current and earlier format of the journal, Studies in Soviet Thought (1961-1992). He was likewise a member of the international editorial board of the companion monograph series Sovietica.

A scholar with wide-ranging interests in European philosophy Professor Kline contributed most crucially to the study, in the United States, of Russian and, in part, Soviet philosophy. Apart from his own numerous writings devoted to Russian philosophy and philosophers Kline spared no effort in advancing the cause of Russian thought by his translations of works by Russian philosophers (and poetsBrodsky, among others, some of whose verses he managed to smuggle out of the Soviet Union). In this regard a milestone in his career was his unsung role as the de facto editor-in-chief - as well as active participant in the preparation-of the three volume anthology entitled Russian Philosophy (first edition 1965), still unique in its kind, ranging from Skovoroda to a 1960 Soviet text on diamat.

Over the years, Kline submitted pieces to the journal, the most recent dating from 2011 (concerning Shestov) and 2012 (an account of his discussions with J.M. Bocheński concerning Marxism, Soviet philosophy, and philosophical sovietology).

For those who were fortunate to know him personally, it was striking how his intellectual energy and scholarly rigor blended harmoniously with an unparalleled personal enthusiasm for his subject, in particular his profound attachment to Russian culture.

An overview of Kline's career and his many works in different genres is available at http://en.wikipedia.org/wiki/George_Kline. 